\title{
GENIPIN-CROSSLINKED FIBRIN HYDROGELS AS A POTENTIAL ADHESIVE TO AUGMENT INTERVERTEBRAL DISC ANNULUS REPAIR
}

\author{
R.M. Schek ${ }^{\S}$, A.J. Michalek ${ }^{\S}$ and J.C. Iatridis* \\ School of Engineering, University of Vermont, Burlington, VT, USA
}

${ }^{\S}$ These authors contributed equally to this manuscript.

\begin{abstract}
Treatment of damaged intervertebral discs is a significant clinical problem and, despite advances in the repair and replacement of the nucleus pulposus, there are few effective strategies to restore defects in the annulus fibrosus. An annular repair material should meet three specifications: have a modulus similar to the native annulus tissue, support the growth of disc cells, and maintain adhesion to tissue under physiological strain levels. We hypothesized that a genipin crosslinked fibrin gel could meet these requirements. Our mechanical results showed that genipin crosslinked fibrin gels could be created with a modulus in the range of native annular tissue. We also demonstrated that this material is compatible with the in vitro growth of human disc cells, when genipin:fibrin ratios were $0.25: 1$ or less, although cell proliferation was slower and cell morphology more rounded than for fibrin alone. Finally, lap tests were performed to evaluate adhesion between fibrin gels and pieces of annular tissue. Specimens created without genipin had poor handling properties and readily delaminated, while genipin crosslinked fibrin gels remained adhered to the tissue pieces at strains exceeding physiological levels and failed at $15-30 \%$. This study demonstrated that genipin crosslinked fibrin gels show promise as a gap-filling adhesive biomaterial with tunable material properties, yet the slow cell proliferation suggests this biomaterial may be best suited as a sealant for small annulus fibrosus defects or as an adhesive to augment large annulus repairs. Future studies will evaluate degradation rate, fatigue behaviors, and long-term biocompatibility.
\end{abstract}

Keywords: Fibrin, genipin, hydrogel, crosslinker, annular repair, biomaterial, sealant, adhesive, intervertebral disc.

\author{
*Address for correspondence: \\ James C. Iatridis \\ Leni and Peter W. May Department of Orthopaedics \\ Mount Sinai School of Medicine \\ One Gustave L. Levy Place, Box 1188 \\ New York, NY 10029-6574, USA
}

Telephone Number: 212-241-1517

E-mail: james.iatridis@mssm.edu

\section{Introduction}

Low back pain is a serious public health problem in the US affecting more that $25 \%$ of adults (Deyo et al., 2006). For cases in which this pain stems from the intervertebral disc (IVD), current surgical treatments include spinal fusion, total disc replacement, and discectomy. Unfortunately, these procedures do not repair the disc or restore its original function and may further limit mobility or otherwise alter the biomechanics of the spine which can lead to adjacent segment degeneration (Lee, 1988; Schlegel et al., 1996). Newer treatments for damaged IVDs include strategies to replace and regenerate the nucleus pulposus (NP), the central, gelatinous region of the IVD (Di Martino et al., 2005; Sebastine and Williams, 2007; Hegewald et al., 2008). These techniques are likely to have limited success without adequate repair of the annulus fibrosus (AF), the outer ring of the IVD. The AF is necessarily damaged during surgery to remove or repair the NP, and to a lesser extent from discography procedures (Carragee et al., 2009), and yet a functional, intact AF is key to preventing re-herniation of the NP and retention of any NP replacement device (Alini et al., 2002; Wilke et al., 2006). Thus, it is possible that NP replacement approaches could be augmented by incorporating AF repair. A successful method to repair the AF could also be useful for repairing small needle punctures, such as those that occur for discography or delivery of therapeutics.

Methods for repairing damaged AF are currently limited largely to sutures and modified sutures, which do not compensate for the loss of AF tissue or restore the lost biomechanical properties (Bron et al., 2009a). An appealing alternative is the development of a tissue engineered material to repair the gap in the AF and contain the NP or its replacement. If such a material were degradable, it would ultimately be replaced with host tissue; to fill a large defect in the AF, the material may be seeded with progenitor cells, such as mesenchymal stem cells. An ideal material would need to meet the following three requirements: match the mechanical properties of the AF tissue, allow the growth of disc cells, and adhere to the surrounding tissues under physiological levels of strain. A number of materials have been investigated for this purpose including hydrogels, bioglass, collagen, silk and degradable polymers such as polycaprolactone and polyglycolic acid (Sato et al., 2003; Mizuno et al., 2004; Nerurkar et al., 2007; Chang et al., 2007; Shao and Hunter, 2007; Helen and Gough, 2008; Wan et al., 2008). While many of these materials show promise, none have satisfactorily addressed the need for fixing the implanted material within the annular defects. To ensure a biomaterial remains in place and encourage the 
formation of new tissue, it is critical that any material be able to strongly adhere and be fully integrated with the native annulus tissue.

We hypothesize that a crosslinked hydrogel can meet the requirements for annular tissue repair. Hydrogels are useful in a wide range of tissue engineering applications due to their high water content, biocompatibility, ease of cell seeding, and mechanical properties that mimic soft tissue (Lavik and Langer, 2004; Ahmed et al., 2008). Delivery of a hydrogel is also straightforward as it can be injected in liquid form and sets in situ over the course of several minutes. This property allows its use in irregularly shaped defects. Additionally, a hydrogel could be used in conjunction with other porous biomaterials to improve structure and expand the possibilities for cell seeding. The major limitation of a hydrogel may be their somewhat poor mechanical properties. An appropriately chosen crosslinker, however, can increase the stiffness of the gel such that it closely matches the native tissue. Just as importantly, the crosslinker serves to chemically connect the proteins in the hydrogel with the native proteins in the disc, thus "bridging" the disrupted collagen fibers.

For this work, we have chosen to employ a crosslinked fibrin gel. The components of fibrin, fibrinogen and thrombin, can be purified from human plasma, and fibrin glue has a long history of clinical use in Food and Drug Administration (FDA) approved products such as Tisseel®, Evicel $^{\mathrm{TM}}$, and Crosseal ${ }^{\mathrm{TM}}$. Additionally, fibrin has shown to be an excellent scaffold for cell delivery and tissue ingrowth in a number of tissue engineering applications (for review, see Ahmed et al., 2008). Of specific relevance to connective tissues such as the AF, fibrin has been used to engineer muscle (Hecker et al., 2005; Huang et al., 2005; Nieponice et al., 2007; Rowe et al., 2007), skin (Hojo et al., 2003; Balestrini and Billiar, 2006;), cartilage (Passaretti et al., 2001; Connelly et al., 2004; Johnson et al., 2004; Mesa et al., 2006; Peretti et al., 2006; Eyrich et al., 2007), and connective tissue (Chong et al., 2007; Hankemeier et al., 2007). Recently, fibrin has been shown to be an effective carrier to deliver stem cells to denucelated discs (Allon et al., 2010) and to improve the structure and function of surgically damaged IVDs (Buser et al., 2011).

To crosslink the fibrin gel, we have chosen to utilize genipin. Genipin $\left(\mathrm{C}_{11} \mathrm{H}_{14} \mathrm{O}_{5}, \mathrm{FW} 226.23\right)$ is a plant-derived crosslinking agent traditionally used in herbal medicine and as a food dye. While crosslinkers have the capacity to kill cells, genipin is an attractive choice for crosslinking due its relatively low cytotoxicity (Bedran-Russo et al., 2007; Tsai et al., 2000); specifically, genipin has been shown to be 10,000 times less cytotoxic than glutaraldehyde to 3T3 fibroblasts (Sung et al., 1999). Additionally, genipin has anti-inflammatory properties when used as a crosslinker in vivo (Liang et al., 2003; Koo et al., 2006;) and may even protect neuronal cells from stress-induced cytotoxicity (Yamazaki et al., 2009). Genipin is known to crosslink proteins by binding amine groups on adjacent proteins (Touyama et al., 1994; Yao et al., 2004) and has previously been used to crosslink a variety of materials including collagenous tissues (Huang et al., 1998; Sung et al., 2003), chitosan (Mi et al., 2002; Mwale et al., 2005), gelatin (Chen et al., 2005), and fibrinogen electrospun scaffolds (Sell et al., 2008). Recently, it has also been used to crosslink fibrin hydrogels for articular cartilage engineering (Dare et al., 2009). Genipin crosslinked fibrin gels were shown to be compatible with chondrocytes in vitro and to inhibit the inflammatory response when implanted in rats (Dare et al., 2009).

In this work, we proposed to determine the suitability of a genipin crosslinked fibrin hydrogel for repair of the annulus fibrosus. Particularly, we sought to determine whether such a hydrogel could meet the three requirements of matching the AF tissue properties, supporting cell growth, and strongly adhering to native tissue. To investigate this first requirement, we measured the modulus of gels with varied formulation and compared them to samples of human AF tissue. We then performed in vitro experiments in which human disc cells were cultured on gels and their survival measured. Finally, to evaluate adhesion, we created gel samples that were allowed to crosslink in contact with AF tissue and measured the strain at which this adhesion failed. The current study is focused on developing an adhesive biomaterial with potential to be used as a sealant (rather than full cell seeded scaffold) for small AF defects or as an adhesive to augment repair of large AF repairs with other biomaterials. The material was optimized to match native tissue material properties, while maintaining suitable adhesion to native tissue and low cytotoxicity.

\section{Materials and Methods}

\section{Gel fabrication}

Fibrinogen isolated from bovine plasma (Sigma-Aldrich, St. Louis, MO, USA) was dissolved in phosphate buffered saline (PBS) at concentrations of 200, 250, or $300 \mathrm{mg} /$ $\mathrm{mL}$; above $300 \mathrm{mg} / \mathrm{mL}$ the fibrinogen could not be readily dissolved. Thrombin isolated from bovine plasma (SigmaAldrich) was dissolved in PBS at a concentration of $100 \mathrm{U} /$ mL. Genipin (Wako, Richmond, VA, USA) was dissolved in dimethyl sulfoxide (Fisher Scientific, Hampton, NH, USA) at a concentration of $400 \mathrm{mg} / \mathrm{mL}$. The fibrinogen was pipetted into molds as specified below; thrombin and genipin were mixed together and then added to the fibrinogen in quantities specified below. Genipin quantities were determined such that desired genipin:fibrin weight ratios could be obtained (i.e., to create a 0.25:1 gel for cell culture testing, $600 \mu \mathrm{L}$ of $200 \mathrm{mg} / \mathrm{mL}$ fibrinogen was mixed with $75 \mu \mathrm{L}$ of genipin). The gels were allowed to rest for $24 \mathrm{~h}$ to completely crosslink prior to mechanical testing or cell seeding. Pilot studies (not shown) demonstrated that a genipin:fibrin concentration ratio of $1: 1$ and $2: 1$ resulted in nearly zero cell survival. Therefore, we have tested ratios of $0.25: 1,0.5: 1$, and $0: 1$ as a control. The ratio of $0: 1$ was fibrin gel alone. A pilot study, which used a spectrophotometer to determine the relative number of crosslinks in genipin-containing gels, indicated that the use of larger amounts of genipin did not lead to the formation of additional crosslinks beyond a genipin:fibrin ratio of approximately 10:1 (Sung et al., 1999; Starcher, 2001; Chang et al., 2003). Therefore, we assumed that at the sub-saturating genipin:fibrin ratios used, the vast majority 

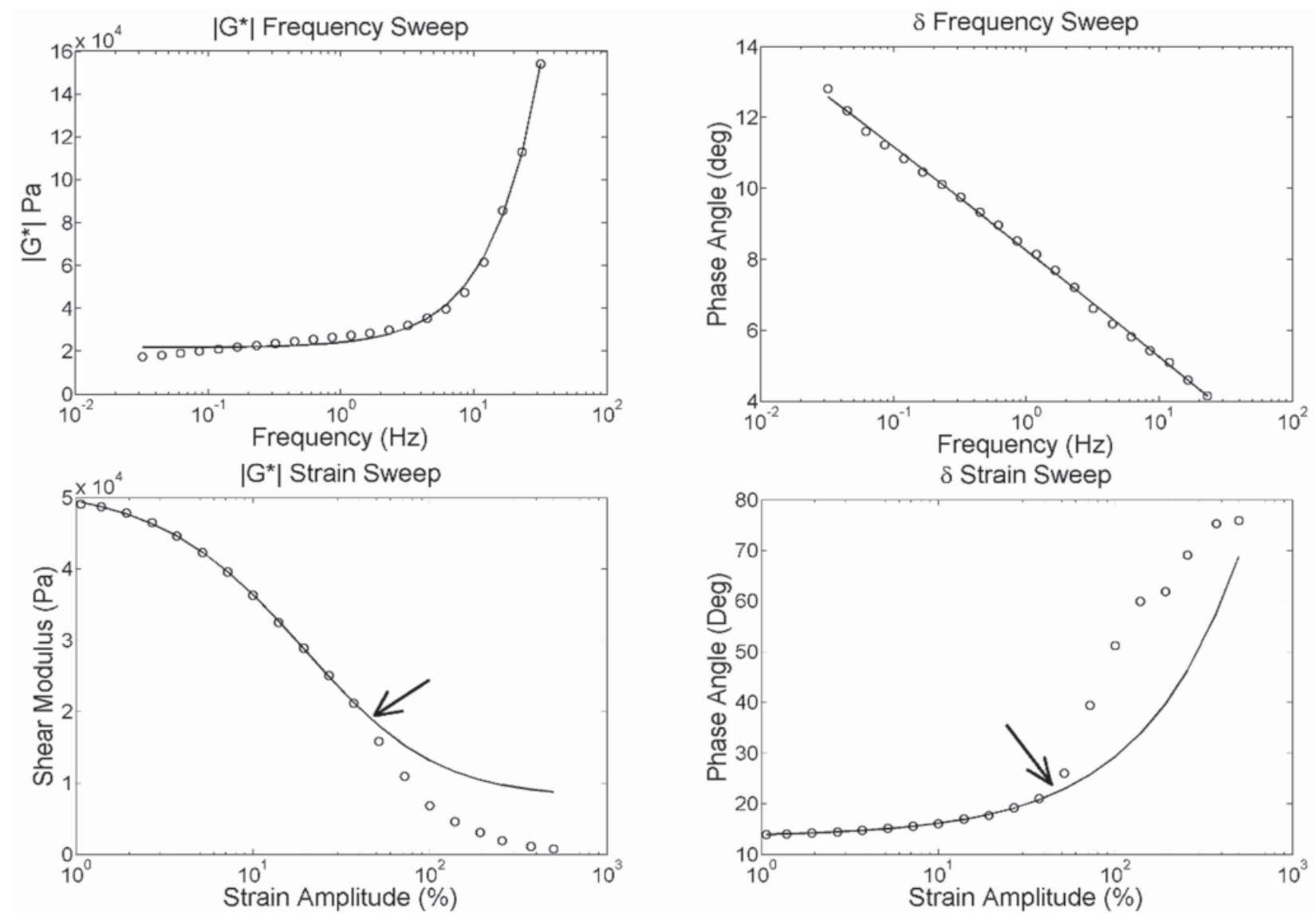

Fig. 1. Representative model fits, -, to experimental data, o. Black arrows indicate slippage between the specimen and the rheometer platens. Measurements after this point were not analyzed.

of the genipin in the gel would have formed crosslinks and be bound to amine groups on the fibrin (Touyama et al., 1994; Yao et al., 2004).

\section{Rheological testing}

Samples for rheometer testing were created using custom made Teflon molds with cylindrical wells $5 \mathrm{~mm}$ in diameter and $5 \mathrm{~mm}$ deep. Into each well, $50 \mu \mathrm{L}$ of the fibrinogen was pipetted, followed by $5 \mu \mathrm{L}$ of thrombin mixed with sufficient genipin to create the desired ratio of genipin:fibrin. The resulting gel specimens were approximately $2.5 \mathrm{~mm}$ thick.

Gel dynamic stiffness tests were carried out using a rheometer (TA Instruments, www.tainstruments.com) equipped with flat platens covered with 100 grit sand paper (Gator Grit; www.gatorfinishing.com) and a humidified chamber. The test protocol was adapted from Bron et al. (Bron et al., 2009b) and consisted of a 20 min equilibration at $0.1 \mathrm{~N}$ of axial compression followed by a dynamic frequency sweep at $10 \%$ strain from 0.032 to $32 \mathrm{~Hz}$. The protocol concluded with a strain sweep at $0.5 \mathrm{~Hz}$ from 1 to $500 \%$ strain. Dynamic modulus magnitude, $\left|G^{*}\right|$, and phase angle, $\delta$, were calculated at each point of the frequency and strain sweeps. Parameters from both sweeps demonstrated power law dependence on frequency and strain, and were thus characterized by fitting the following functions using a least squares routine in Matlab (Mathworks Inc., Natick, MA, USA) (Fig. 1).

$$
\begin{aligned}
& \left|G^{*}\right|(\omega)=a+b \omega^{\alpha_{\left|G^{*}\right|}}, \delta(\omega)=c+d \omega^{\alpha_{\delta}} \\
& \left|G^{*}\right|(\gamma)=j+k(\gamma+\Gamma)^{\beta_{\left|G^{*}\right|}}, \delta(\gamma)=m+n \gamma^{\beta_{\delta}}
\end{aligned}
$$

Five parameters from the model fit were used to compare $\left|G^{*}\right|$ and $\delta$ across groups, and with human AF tissue. For the frequency sweep, dynamic modulus was characterized by its value at $1 \mathrm{~Hz},\left|G^{*}\right|_{1 \mathrm{~Hz}}$ which is equivalent to parameters $a+b$, and its dependence on frequency was characterized by power law exponent $t, \alpha_{\mathrm{G}^{*} \mid}$. Phase angle was likewise characterized by its value at $1 \mathrm{~Hz}, \delta_{1 \mathrm{~Hz}}$ which is equivalent to parameters $c+d$, and its power law exponent, $\alpha_{\delta}$. For the strain sweep, accurate description of the experimental data also required a strain offset term. Therefore, dynamic modulus during the strain sweep was characterized by strain offset, $\Gamma$, modulus at the offset strain, $\left|G^{*}\right|_{\Gamma 0}$, and strain dependence exponent $\beta_{\left|G^{*}\right|}$. Phase angle during the strain offset was accurately described with 2 parameters, its value at $1 \%$ strain, $\delta_{1 \%}=m+n$, and strain dependence exponent for $\delta, \beta_{\delta}$. The dependence of these nine parameters on fibrin and genipin concentrations was assessed using a two way ANOVA with factors fibrin concentration (200, 250 and $300 \mathrm{mg} / \mathrm{mL}$ ), and relative genipin concentration (i.e., as given by genipin:fibrin ratio of $0: 1,0.25: 1$ and $0.5: 1$ ).

In order to assess the suitability of the genipin crosslinked fibrin gels for tissue repair, the rheological 




Fig. 2. Representative plot of load cell voltage $v s$. applied strain for a bi-layered lap test. Schematics show bi-layered specimen initially (a), under shear (b), at initial failure (c), and completely failed (d).

testing protocol was also performed on thirteen human $\mathrm{AF}$ specimens with an average age of $53 \pm 16$ years. The average Thompson grade of these discs was 3 , indicating a tissue with mild to moderate degeneration. Model fit parameters were compared between the gel groups and the native tissue using unpaired $t$-tests with the significant $p$ value adjusted to $<0.005$ to account for multiple comparisons.

\section{Lap testing}

Gel-tissue adhesion was characterized by a modified lap test carried out using a custom built axial testing machine using a linear actuator (www.physikinstrumente.com). The upper and lower faces of the bi-layered specimen were adhered to brass platens using cyanoacrylate glue (Loctite $410 \mathrm{Gel}$ ). In order to ensure that the test was measuring adhesion and not boundary friction, platen spacing was adjusted to minimize axial force on the specimen. Specimen thickness was measured with calipers in order to calculate shear displacements required for given strains. One platen was then displaced in order to shear the specimen at a constant rate of $1 \% / \mathrm{s}$ to $100 \%$. Pilot studies showed that this magnitude was sufficient to ensure specimen failure. Specimen failure strain was assessed by identifying peak stress on the resulting load versus strain plot (Fig. 2). Mode of failure was determined visually for each specimen and recorded.

\section{Cell culture}

Human AF cells were obtained from tissue removed by a surgeon performing discectomy procedures with IRB approval and patient consent. Disc tissue from the outer AF only was obtained from patients with an average age of $45 \pm 14$ years; discs were graded as either moderate or severely degenerate. The harvested AF tissue was first rinsed in a wash solution of $1.5 \%$ fungizone (Gibco/ Invitrogen-Life Technologies, www.invitrogen.com) and $3 \%$ penicillin-streptomycin (Gibco) in phosphate buffered saline (Gibco) and then digested in $50 \mathrm{~mL}$ of Dulbecco's Modified Eagle Medium (DMEM, Gibco) containing 0.2\% pronase (Sigma-Aldrich), 1\% penicillin-streptomycin, and $0.5 \%$ fungizone for $1 \mathrm{~h}$ at $37{ }^{\circ} \mathrm{C}$. After $1 \mathrm{~h}, 0.2 \%$ collagenase (Sigma-Aldrich) was added to the digest solution and the digest was continued for an additional 4 $\mathrm{h}$. The digest was then filtered through a $70 \mu \mathrm{m}$ nylon filter, centrifuged, and cells resuspended and plated into flasks. Cells were fed every 3-4 d with growth medium (DMEM supplemented with 10\% fetal bovine serum (Gibco), 1\% penicillin-streptomycin, $0.5 \%$ fungizone, and $50 \mu \mathrm{g} / \mathrm{mL}$ ascorbic acid (Sigma-Aldrich)). Cells used for viability experiments were P3-P4.

Gels were created in the wells of 6-well tissue culture plates. Into each well, $600 \mu \mathrm{L}$ of 200,250 , or $300 \mathrm{mg} /$ $\mathrm{mL}$ fibrinogen was pipetted. Thrombin $(60 \mu \mathrm{L} /$ well $)$ and genipin were added to obtain genipin: fibrin of $0: 1,0.25: 1$, or $0.5: 1(n=3)$. After $24 \mathrm{~h}$, the gels were rinsed with PBS and 30,000 human disc cells were plated in each well. Cells were fed with growth medium every two days and allowed to grow on the gels for 1,3 , or $7 \mathrm{~d}$ and then rinsed with PBS. To assess the number of live cells adhered on the surface of the gels, they were incubated with a solution of $4 \mathrm{mM}$ calcein in PBS (Invitrogen) for $30 \mathrm{~min}$ at $37^{\circ} \mathrm{C}$. Calcein is transported only through the membrane of live cells and is commonly utilized to assess number of live cells (Sun et al., 2010). Calcein positive cells were imaged on an Olympus (Tokyo, Japan) upright BX microscope equipped with a Chroma GFP filter cube and a Leica 

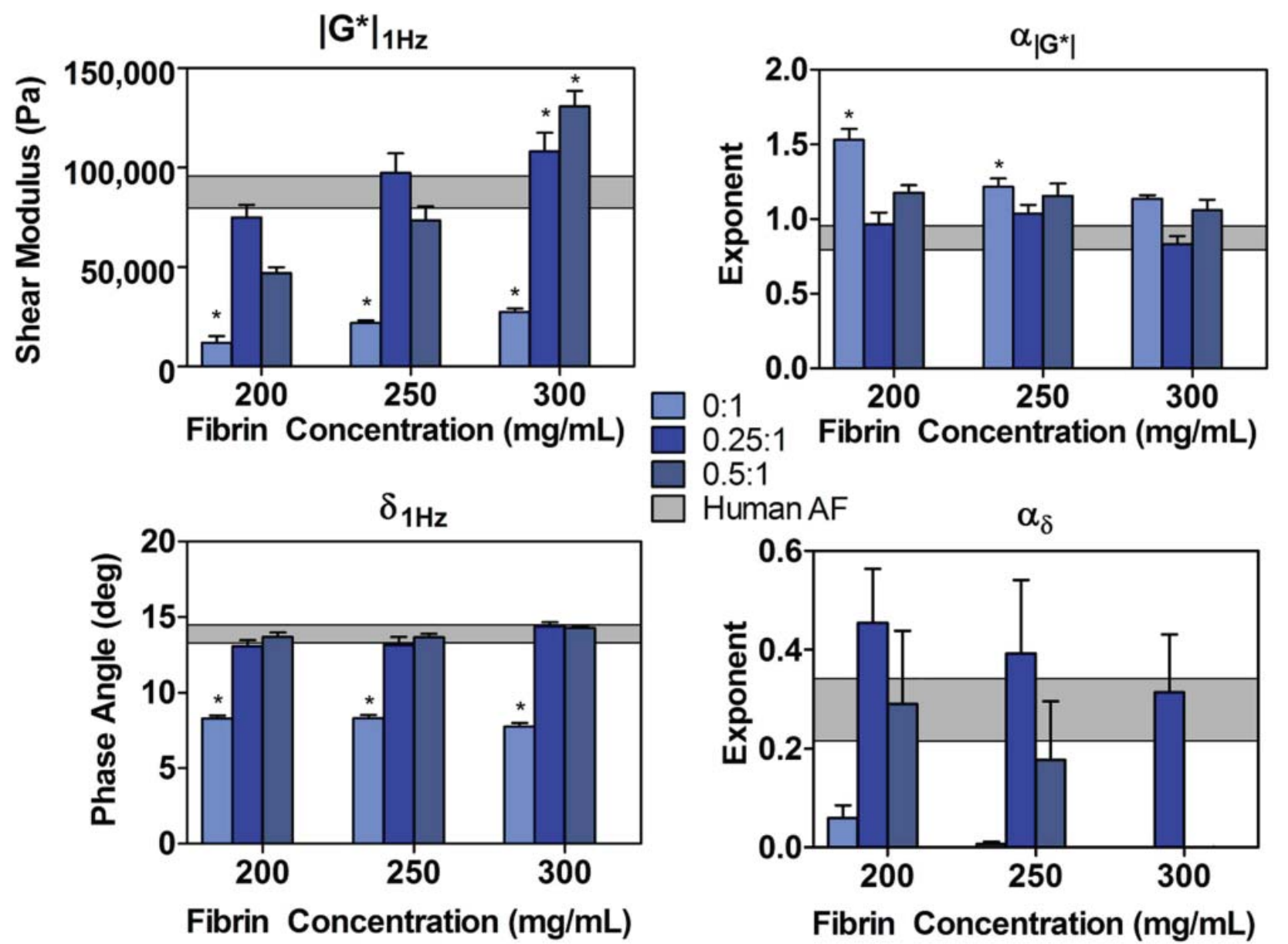

$0.5: 1$

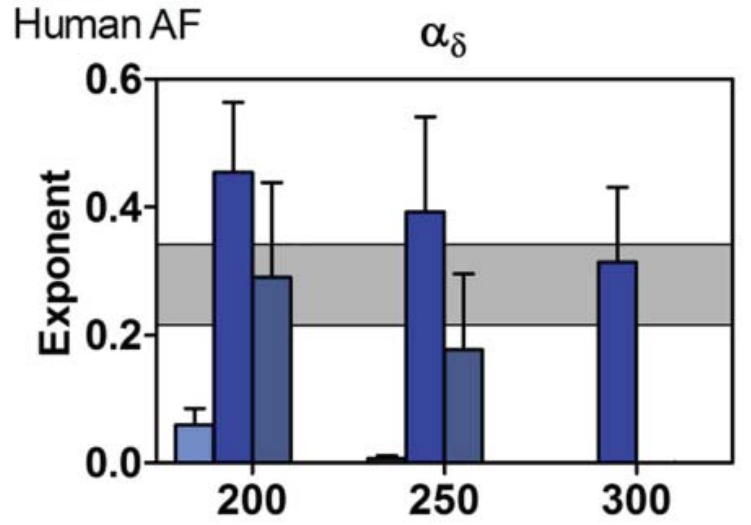

Fibrin Concentration $(\mathrm{mg} / \mathrm{mL})$

Fig. 3. Average frequency sweep model fit parameters \pm SEM for gels with varying fibrin concentrations and genipin to fibrin ratios. * indicates significantly different from human AF $(p<0.005)$.

R3 camera. Photographs were processed using ImageJ (National Institutes of Health, Bethesda, MD, USA); they were thresholded and the total number of cells was counted. From each experimental well, five fields of view were captured and counted. For each gel formulation at each time point, a total of 15 values were averaged and standard error calculated. The differences in the number of calcein positive cells were compared using paired $t$ tests with $p<0.05$ significant. To determine whether cell number had increased over the duration of the culture period, the number of live cells on day 1 was compared to the number of live cells on day 7 .

\section{Results}

\section{Gel fabrication}

Gels formed readily in both the Teflon molds and cell culture dishes. Gels set in less than $5 \mathrm{~min}$ and evidence of crosslinking (appearance of dark blue color) was apparent within $2 \mathrm{~h}$. Following the $24 \mathrm{~h}$ curing, crosslinked gels were very firm to the touch and easily removable from the Teflon mold. Gels fabricated without genipin were more difficult to remove from the mold and more easily torn during handling.

\section{Stiffness results from rheological testing}

Rheological testing indicated that material properties of this genipin crosslinked fibrin gel follow power law relationships (c.o.d. $=0.84 \pm 0.28$ ) with strain amplitude and frequency, the parameters of which are tuneable by varying fibrin concentration and genipin:fibrin ratio. The two way ANOVA showed that nearly all parameters were significantly affected by fibrin concentration, genipin:fibrin ratio, and their interaction ( $p$-values are summarized in Table 1, and parameter values are in Figs. 3 and 4), although some exceptions were found particularly for the strain sensitivity of several material parameters.

Gels made with $250 \mathrm{mg} / \mathrm{mL}$ of fibrin and either $0.25: 1$ or $0.5: 1$ genipin:fibrin appear to be the most suitable for mimicking the shear behavior of native tissue, as these samples were not significantly different from human AF in any of the nine calculated parameters. The frequency sweep showed that genipin crosslinked fibrin gels generally demonstrate greater strain rate stiffening (increase in $\left|G^{*}\right|$ with increasing frequency) than the native tissue, with significance achieved either without genipin or with $0.5: 1$ genipin:fibrin at lower fibrin concentrations. Strain rate viscosity effects (change in $\delta$ with increasing frequency) were not significantly different from native in any of the gel groups. The strain dependency exponents, $\beta_{\left|\mathrm{G}^{*}\right|}$ and $\beta_{\delta}$, were not significantly different from native $\mathrm{AF}$ for most gel 




Fibrin Concentration $(\mathrm{mg} / \mathrm{mL})$

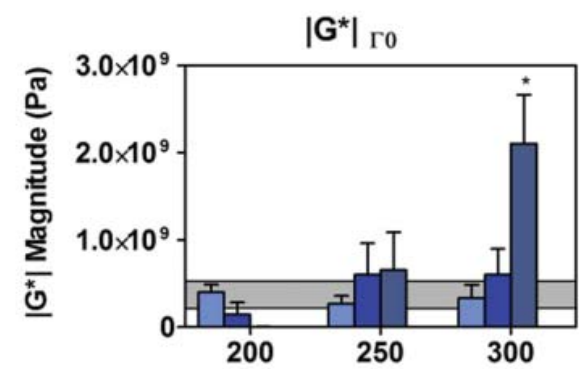

Fibrin Concentration $(\mathrm{mg} / \mathrm{mL})$



Fibrin Concentration $(\mathrm{mg} / \mathrm{mL})$

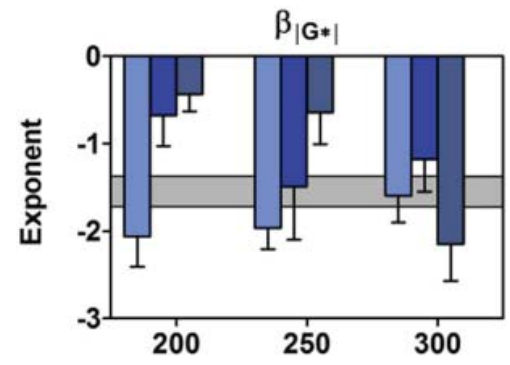

Fibrin Concentration $(\mathrm{mg} / \mathrm{mL})$

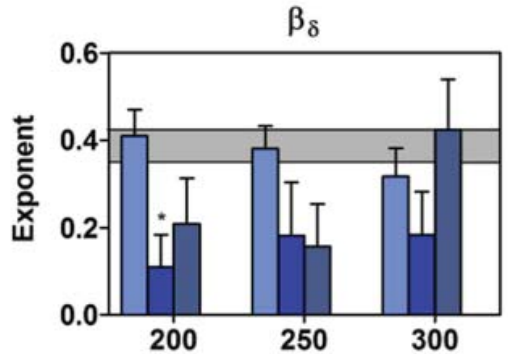

Fibrin Concentration $(\mathrm{mg} / \mathrm{mL})$

Fig. 4. Average strain sweep model fit parameters \pm SEM for gels with varying fibrin concentrations and genipin:fibrin ratios. * indicates not significantly different from human $\mathrm{AF}(p<0.005)$.


Fig. 5. Images of calcein stained cells after $7 \mathrm{~d}$ grown on $200 \mathrm{mg} / \mathrm{mL}$ fibrin gel containing no genipin (A) or with a genipin to fibrin ratio of 0.25:1 (B). Inset of greater magnification to highlight cytomorphology.

Table 1. Two way ANOVA showing effects of fibrin and relative genipin concentrations on frequency and strain

\begin{tabular}{|c|cc|cc|ccc|cc|}
\hline \multicolumn{3}{|c|}{ Frequency } & \multicolumn{1}{|l|}{ Strain } \\
& $\begin{array}{c}\text { Modulus } \\
\left.G^{*}\right|_{1 \mathrm{~Hz}}\end{array}$ & $\alpha_{\mathrm{G}^{*}}$ & $\delta_{1 \mathrm{~Hz}}$ & $\alpha_{\delta}$ & $\Gamma$ & $\left|G^{*}\right|_{\Gamma 0}$ & $\beta_{G^{*} \mid}$ & $\delta_{1 \%}$ & $\beta_{\delta}$ \\
\hline Fibrin & $<0.001$ & $<0.001$ & 0.080 & $<0.001$ & 0.015 & 0.709462 & $<0.001$ & 0.436 & 0.050 \\
Relative & $<0.001$ & $<0.001$ & 0.008 & $<0.001$ & 0.567 & 0.467944 & $<0.001$ & 0.045 & $<0.001$ \\
Genipin & & & & & & & & \\
Interaction & 0.074 & $<0.001$ & 0.541 & 0.018 & 0.995 & 0.546036 & $<0.001$ & 0.352 & 0.088 \\
\hline
\end{tabular}


groups. Both magnitude parameters, as calculated by both the frequency and strain sweeps, were significantly lower in the gels without genipin at all fibrin concentrations.

\section{Adhesion results from lap testing}

The modified lap test resulted in an average failure strain \pm SD of $26 \pm 7 \%$. Detachment at the specimen-platen interface was not observed in any specimen. The mode of specimen failure was equally distributed between slippage of the gel-tissue interface and fracture of the gel itself.

\section{Cell viability}

Disc cells assumed a spindle morphology when grown on fibrin gel alone (i.e., a ratio of $0: 1$ ) that is typical when grown on tissue culture plastic (Fig. 5). When grown on the genipin containing gels, the disc cells assumed a round shape and did not exhibit cell processes extending across the surface of the gel. This difference was observed for all fibrinogen concentrations and genipin:fibrin ratios; the presence of genipin at these levels was sufficient to alter the morphology.

The number of live cells was quantified and averaged across 15 fields of view for each condition. Graphs of the cell number over time show similar results for gels with fibrin concentrations of 200 or $250 \mathrm{mg} / \mathrm{mL}$ (Fig. 6). Between day 1 and day 7 , the increase in cell number was statistically significant $(p<0.05)$ for all gels containing no genipin. On the crosslinked gels, we observed the cell number to be similar between days 1 and 3; however, multiplication between days 3 and 7 was more rapid and similar in speed to cells on the gels containing no genipin. For both 200 and $250 \mathrm{mg} / \mathrm{mL}$ gels, higher cells numbers were seen for genipin: fibrin ratios of $0.25: 1$ than for $0.5: 1$. Cell cultured on $300 \mathrm{mg} / \mathrm{mL}$ gels multiplied more slowly that those grown on 200 or $250 \mathrm{mg} / \mathrm{mL}$, even in the absence of genipin. Statistical analysis showed that the increase in cell number between day 1 and day 7 was significant for all the gels with a genipin:fibrin ratio of $0.25: 1$. However, for gels with a genipin: fibrin ratios of $0.5: 1$, only the 200 $\mathrm{mg} / \mathrm{mL}$ gel showed a significant increase in cell number.

\section{Discussion}

In this work, we have been guided by the principle that an annular repair material should meet three specifications: have a modulus that matches the native annulus tissue, support the growth of disc cells, and maintain adhesion to tissue under physiological strain levels. We hypothesized that a genipin crosslinked fibrin gel could meet these requirements. Our mechanical results showed that genipin crosslinked fibrin gels could be created with a modulus in an appropriate range, and that genipin was required to achieve a modulus matching that of native AF tissue across a wide range of strain rates and amplitudes. By altering fibrin concentration and the genipin:fibrin ratio, the modulus of the gel is tuneable to specific applications. We also demonstrated that this material is compatible with the in vitro growth of human disc cells, when genipin:fibrin ratios were $0.25: 1$ or less. Lastly, the results of our lap tests demonstrated that genipin crosslinked fibrin gels remained
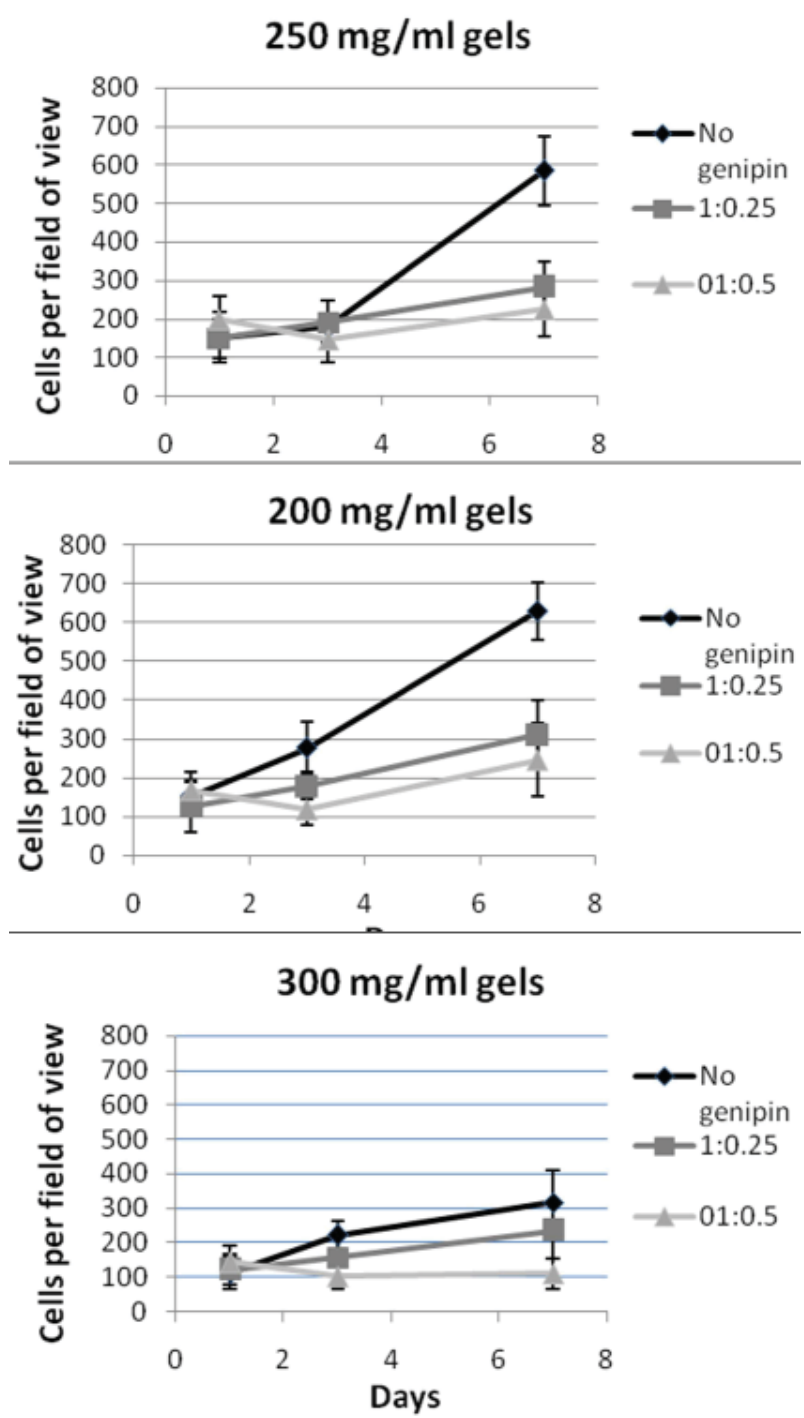

Fig. 6: Graphs demonstrating the multiplication of cells on the crosslinked fibrin gels over time; cell number is per field of view.

adhered to pieces of annular tissue at physiological strains of 5-10\% (Krismer et al., 1996; Costi et al., 2007; O'Connell et al., 2010) and failed at higher strains of 15-30\%.

Cell viability testing demonstrated that the presence of genipin in the gels results in rounded cell morphology and slows cell proliferation. An elongated morphology and the presence of long cell processes are key features of AF cells in their native matrix (Errington et al., 1998). Because these processes are important for proper AF cell function (Errington et al., 1998; Bruehlmann et al., 2002), the ideal biomaterial should likewise facilitate this cell morphology. These results show that AF cells can survive and proliferate at a retarded but statistically significant rate on gels with a genipin to fibrin ratios of $0.25: 1$ or less, yet the cell morphology was rounded. Further evaluation is required to evaluate if normal AF cell morphology can be achieved in the presence of this fibrin-genipin hydrogel in a 3D culture system that more closely represents in situ repair, or with lower genipin concentrations. Future studies 
are also warranted to evaluate the compatibility of this material for cells types where a rounded morphology is normal, such as for chondrocytes or stem cell condensation.

An optimal material must simultaneously balance mechanical properties and adhesion, which are improved by the addition of genipin, with biological properties, which are improved by lowering genipin concentrations. In this work, our goal was to map out that design space by probing the limits of these two variables. Because these experiments determined levels at which cells could survive, but not thrive, we know now the maximum concentration and that lower levels will be preferable for cell survival and growth. Interactions between AF cells and their matrix are complex; in addition to the chemical make-up of the matrix, its stiffness, alignment, and surface chemistry, as well as time in culture, all affect cell attachment and morphology (Shao and Hunter, 2007; Yang et al., 2009; Attia et al., 2011; Koepsell et al., 2011; Zhang et al., 2011). Thus, it is possible that the cell behavior seen in this work may derive from surface properties or culture time, rather than being solely a result of the genipin to fibrin ratio. The abnormal AF cell behavior could also be caused by the unique surface structure of the crosslinked gel. The presence of the genipin crosslinks may affect how cells adhere and spread upon the surface. However, other investigations have shown that genipin crosslinked scaffolds do support cellular growth (Mekhail et al., 2010), and we therefore hypothesize that the behavior of AF cells in the presence of genipin crosslinked fibrin gels will be improved in a more three dimensional culture environment, and/or with different concentrations. Future work will investigate properties of gels with lower genipin concentrations and the effect on cell viability and phenotype as well as the capacity of this crosslinked hydrogel to be used to augment adhesion of other biomaterials that may be better able to promote AF cell morphology and proliferation in situ.

Another interesting phenomenon noted in the cell culture study was the tendency, in the gels containing genipin, for little cell proliferation in the first $48 \mathrm{~h}$, following by a slow increase in cell number. While we did not specifically investigate a mechanism, two possibilities likely exist for this trend. Firstly, if any free genipin in the media was hindering cell growth, it would have been largely removed by the media change. Secondly, a number of cells may have died during seeding and a few days were required for cell number to rebound to initial seeding density. Only after this happened, could an increase in cell number become apparent.

In this work, we primarily reported genipin concentration as the ratio of genipin to fibrin. Genipin crosslinks proteins (including fibrin) by binding amine groups on adjacent proteins; thus degree of crosslinking is dependent on the percentage of amine groups that are bound to a genipin molecule (Touyama et al., 1994; Yao et al., 2004). Unlike absolute genipin concentration, the ratio of genipin to fibrin gives us a relative measure of the extent of fibrin crosslinking. Additionally, our cell culture testing showed that rates of cell survival in gels depended upon genipin to fibrin ratios rather than absolute genipin concentration. For instance, a similar number of cells survived in the 200 $\mathrm{mg}$ fibrin/mL gel with a genipin to fibrin ratio of $0.25: 1$ as in the $300 \mathrm{mg}$ fibrin/mL with a ratio of $0.25: 1$ gels. This was despite the fact that the absolute genipin concentration was 1.5 times greater in the latter gel. We hypothesize that cell toxicity largely results from genipin which remains unbound to fibrin. Accordingly, gels with higher ratios of genipin to fibrin had larger amounts of free genipin, which resulted in fewer numbers of viable cells in these constructs. Overall, this indicates that the ratio of genipin to fibrin is a more relevant variable than the absolute genipin concentration.

The results of rheological testing demonstrated power law relationships with both strain rate and amplitude for the genipin crosslinked hydrogel and for human AF tissue. Assessing these behaviors across a broad range of loading conditions is essential for determining an ideal material formulation for repairing the AF. The similarities of material constants of the hydrogel (of certain formulations) with human AF tissue demonstrates strong mechanical compatibility over a large range of frequencies and strain amplitudes. The shear modulus of the hydrogel depends on both the fibrin concentration and the ratio of genipin to fibrin. Increasing the fibrin concentration leads to an apparently linear increase in the modulus of the gels. Increasing the ratio of fibrin to genipin, however, does not lead to such a regular increase in modulus. Specifically, we found that, for a given fibrin concentration, modulus increases steeply from $0: 1$ to $0.25: 1$ genipin to fibrin; further increases in modulus were seen only when this ratio was substantially increased to 4:1 (data not shown because cells did not remain viable at this high genipin to fibrin ratio). Further exploration of mechanical behavior at lower genipin ratios may show that we can maintain mechanical properties while improving cell survival. Adjustments in fibrin concentration and/or the ratio of genipin to fibrin allow us multiple formulation options to create a gel with the desired modulus.

Genipin crosslinked fibrin gels have met basic design requirements for acute annular repair as outlined above, although future work must focus on longer term behavior before these gels can be considered for clinical use. Most importantly, we must understand how the material might perform under long-term implantation conditions including characterizing both its fatigue life and its biodegradation profile. Additional bench testing should also include evaluating the gels performance within an intact vertebral motion segment. Genipin and fibrin's history of use along with the cell viability data presented here suggest that this material has potential clinical utility. However, these data do not establish true biocompatibility or the specific effects of the gel on disc cell phenotype, which both need to be fully understood. Future cell culture studies focusing on gene expression will require the use of AF cells at the lowest possible passage since phenotypic changes have been observed when disc cells are cultured for extended periods (Chou et al., 2006). These in vitro tests cannot fully predict the mechanical or biological performance of these gels in vivo and so future evaluation in an animal injury model is needed.

The biomechanical compatibility, "tunable" material properties, and strong adherence to native tissues demonstrate high utility of this biomaterial for AF repair 
as well as potential repair of other tissues. The "tunable" nature of the mechanical properties indicates that we can maintain a desired modulus by simultaneously adjusting the fibrinogen content and the ratio of genipin to fibrin so that we can optimize the formulation of AF repair or potentially for other tissues with similar design requirements. The gel's formulation can also be altered as we learn more about its degradation and fatigue behavior over time. For example, the gel could be augmented to improve its performance with enzymes to slow degradation. The relatively rapid set time of the gels also enables refinement of delivery and application techniques. For example, the genipin crosslinked fibrin gel may be used as a sealant to repair punctures with injection techniques. The strong adherence of genipin crosslinked fibrin gel to human AF tissues further indicates the gel may be used for larger AF defects in combination with recently developed fibrous materials, creating a composite scaffold with excellent stiffness and adhesive properties (Mizuno et al., 2004; Chang et al., 2007; Wan et al., 2007; Nerurkar et al., 2009). Additionally, the positive results of recent studies utilizing fibrin to repair IVDs (Allon et al., 2010; Buser et al., 2011) suggest that there could be significant applications for an enhanced, stiffer fibrin-based material in the future. We conclude that genipin crosslinked fibrin gels are effective gap filling biomaterials with tunable material properties and strong adhesion to native tissues with substantial promise to be used as a sealant for small AF defects or as an adhesive to augment other biomaterials for larger AF repairs, although additional testing to evaluate safety and biocompatibility in situ are required.

\section{Acknowledgements}

This project was supported by the National Institutes of Health (R01AR051146). We gratefully acknowledge the assistance procuring surgical tissue samples from Dr. Robert Monsey, and the technical assistance on shear testing from Ms. Kristin Funabashi. A preliminary patent was submitted for this biomaterial.

\section{References}

Ahmed TA, Dare EV, Hincke M (2008) Fibrin: A versatile scaffold for tissue engineering applications. Tissue Eng Part B Rev, in press.

Alini M, Roughley PJ, Antoniou J, Stoll T, Aebi M (2002) A biological approach to treating disc degeneration: Not for today, but maybe for tomorrow. Eur Spine J 11 Suppl 2: S215-220.

Allon AA, Aurouer N, Yoo BB, Liebenberg EC, Buser Z, Lotz JC (2010) Structured coculture of stem cells and disc cells prevent disc degeneration in a rat model. Spine J 10: 1089-1097.

Attia M, Santerre JP, Kandel RA (2011) The response of annulus fibrosus cell to fibronectin-coated nanofibrous polyurethane-anionic dihydroxyoligomer scaffolds. Biomaterials 32: 450-460.
Balestrini JL, Billiar KL (2006) Equibiaxial cyclic stretch stimulates fibroblasts to rapidly remodel fibrin. J Biomech 39: 2983-2990.

Bedran-Russo AK, Pereira PN, Duarte WR, Drummond JL, Yamauchi M (2007) Application of crosslinkers to dentin collagen enhances the ultimate tensile strength. J Biomed Mater Res B Appl Biomater 80: 268-272.

Bron JL, Helder MN, Meisel HJ, Van Royen BJ, Smit TH (2009a) Repair, regenerative and supportive therapies of the annulus fibrosus: Achievements and challenges. Eur Spine J 18: 301-313.

Bron JL, Koenderink GH, Everts V, Smit TH (2009b) Rheological characterization of the nucleus pulposus and dense collagen scaffolds intended for functional replacement. J Orthop Res 27: 620-626.

Bruehlmann SB, Rattner JB, Matyas JR, Duncan NA (2002) Regional variations in the cellular matrix of the annulus fibrosus of the intervertebral disc. J Anat 201: 159-171.

Buser Z, Kuelling F, Liu J, Liebenberg E, Thorne KJ, Coughlin D, Lotz JC (2011) Biological and biomechanical effects of fibrin injection into porcine intervertebraldiscs. Spine (Phila Pa 1976), in press.

Carragee EJ, Don AS, Hurwitz EL, Cuellar JM, Carrino JA, Herzog R (2009) 2009 ISSLS prize winner: Does discography cause accelerated progression of degeneration changes in the lumbar disc: A ten-year matched cohort study. Spine (Phila Pa 1976) 34: 2338-2345.

Chang G, Kim HJ, Kaplan D, Vunjak-Novakovic G, Kandel RA (2007) Porous Silk Scaffolds Can Be Used for Tissue Engineering Annulus Fibrosus. Eur Spine J 16: 1848-1857.

Chang WH, Chang Y, Lai PH, Sung HW (2003) A genipin-crosslinked gelatin membrane as wound-dressing material: In vitro and in vivo studies. J Biomater Sci Polym Ed 14: 481-495.

Chen YS, Chang JY, Cheng CY, Tsai FJ, Yao CH, Liu BS (2005) An in vivo evaluation of a biodegradable genipin-cross-linked gelatin peripheral nerve guide conduit material. Biomaterials 26: 3911-3918.

Chong AK, Ang AD, Goh JC, Hui JH, Lim AY, Lee EH, Lim BH (2007) Bone marrow-derived mesenchymal stem cells influence early tendon-healing in a rabbit Achilles tendon model. J Bone Joint Surg Am 89: 74-81.

Chou AI, Bansal A, Miller GJ, Nicoll SB (2006) The effect of serial monolayer passaging on the collagen expression profile of outer and inner anulus fibrosus cells. Spine (Phila Pa 1976) 31: 1875-1881.

Connelly JT, Vanderploeg EJ, Levenston ME (2004) The influence of cyclic tension amplitude on chondrocyte matrix synthesis: Experimental and finite element analyses. Biorheology 41: 377-387.

Costi JJ, Stokes IA, Gardner-Morse M, Laible JP, Scoffone HM, Iatridis JC (2007) Direct measurement of intervertebral disc maximum shear strain in six degrees of freedom: Motions that place disc tissue at risk of injury. $\mathrm{J}$ Biomech 40: 2457-2466.

Dare EV, Griffith M, Poitras P, Kaupp JA, Waldman SD, Carlsson DJ, Dervin G, Mayoux C, Hincke MT (2009) Genipin cross-linked fibrin hydrogels for in vitro human 
articular cartilage tissue-engineered regeneration. Cells Tissues Organs 190: 313-325.

Deyo RA, Mirza SK, Martin BI (2006) Back pain prevalence and visit rates: Estimates from U.S. National Surveys, 2002. Spine (Phila Pa 1976) 31: 2724-2727.

Di Martino A, Vaccaro AR, Lee JY, Denaro V, Lim MR (2005) Nucleus pulposus replacement: Basic science and indications for clinical use. Spine (Phila Pa 1976) 30: S16-22.

Errington RJ, Puustjarvi K, White IR, Roberts S, Urban JP (1998) Characterisation of cytoplasm-filled processes in cells of the intervertebral disc. J Anat 192: 369-378.

Eyrich D, Brandl F, Appel B, Wiese H, Maier G, Wenzel M, Staudenmaier R, Goepferich A, Blunk T (2007) Long-term stable fibrin gels for cartilage engineering. Biomaterials 28: 55-65.

Hankemeier S, van Griensven M, Ezechieli M, Barkhausen T, Austin M, Jagodzinski M, Meller R, Bosch U, Krettek C, Zeichen J (2007) Tissue engineering of tendons and ligaments by human bone marrow stromal cells in a liquid fibrin matrix in immunodeficient rats: Results of a histologic study. Arch Orthop Trauma Surg 127: 815-821.

Hecker L, Baar K, Dennis RG, Bitar KN (2005) Development of a three-dimensional physiological model of the internal anal sphincter bioengineered in vitro from isolated smooth muscle cells. Am J Physiol Gastrointest Liver Physiol 289: G188-196.

Hegewald AA, Ringe J, Sittinger M, Thome C (2008) Regenerative treatment strategies in spinal surgery. Front Biosci 13: 1507-1525.

Helen W, Gough JE (2008) Cell viability, proliferation and extracellular matrix production of human annulus fibrosus cells cultured within PDLLA/bioglass composite foam scaffolds in vitro. Acta Biomater 4: 230-243.

Hojo M, Inokuchi S, Kidokoro M, Fukuyama N, Tanaka E, Tsuji C, Miyasaka M, Tanino R, Nakazawa H (2003) Induction of vascular endothelial growth factor by fibrin as a dermal substrate for cultured skin substitute. Plast Reconstr Surg 111: 1638-1645.

Huang LL, Sung HW, Tsai CC, Huang DM (1998) Biocompatibility study of a biological tissue fixed with a naturally occurring crosslinking reagent. J Biomed Mater Res 42: 568-576.

Huang YC, Dennis RG, Larkin L, Baar K (2005) Rapid formation of functional muscle in vitro using fibrin gels. J Appl Physiol 98: 706-713.

Johnson TS, Xu JW, Zaporojan VV, Mesa JM, Weinand C, Randolph MA, Bonassar LJ, Winograd JM, Yaremchuk MJ (2004) Integrative repair of cartilage with articular and nonarticular chondrocytes. Tissue Eng 10: 1308-1315.

Koepsell L, Zhang L, Neufeld D, Fong H, Deng Y (2011) Electrospun nanofibrous polycaprolactone scaffolds for tissue engineering of annulus fibrosus. Macromol Biosci 11: 391-399.

Koo HJ, Lim KH, Jung HJ, Park EH (2006) Antiinflammatory evaluation of Gardenia extract, geniposide and genipin. J Ethnopharmacol 103: 496-500.

Krismer M, Haid C, Rabl W (1996) The contribution of anulus fibers to torque resistance. Spine (Phila $\mathrm{Pa}$ 1976) 21: $2551-2557$.
Lavik E, Langer R (2004) Tissue engineering: Current state and perspectives. Appl Microbiol Biotechnol 65: 1-8.

Lee CK (1988) Accelerated degeneration of the segment adjacent to a lumbar fusion. Spine (Phila Pa 1976) 13: $375-377$.

Liang HC, Chang WH, Lin KJ, Sung HW (2003) Genipin-crosslinked gelatin microspheres as a drug carrier for intramuscular administration: In vitro and in vivo studies. J Biomed Mater Res A 65: 271-282.

Mekhail M, Wong KK, Padavan DT, Wu Y, O'Gorman DB, Wan W (2010) Genipin-cross-linked electrospun collagen fibers. J Biomater Sci Polym Ed., in press.

Mesa JM, Zaporojan V, Weinand C, Johnson TS, Bonassar L, Randolph MA, Yaremchuk MJ, Butler PE (2006) Tissue engineering cartilage with aged articular chondrocytes in vivo. Plast Reconstr Surg 118: 41-49.

Mi FL, Tan YC, Liang HF, Sung HW (2002) In vivo biocompatibility and degradability of a novel injectablechitosan-based implant. Biomaterials 23: 181-191.

Mizuno H, Roy AK, Vacanti CA, Kojima K, Ueda M, Bonassar LJ (2004) Tissue-engineered composites of anulus fibrosus and nucleus pulposus for intervertebral disc replacement. Spine (Phila Pa 1976) 29: 1290-1298.

Mwale F, Iordanova M, Demers CN, Steffen T, Roughley P, Antoniou J (2005) Biological evaluation of chitosan salts cross-linked to genipin as a cell scaffold for disk tissue engineering. Tissue Eng 11: 130-140.

Nerurkar NL, Elliott DM, Mauck RL (2007) Mechanics of oriented electrospun nanofibrous scaffolds for annulus fibrosus tissue engineering. J Orthop Res 25: 1018-1028.

Nerurkar NL, Baker BM, Sen S, Wible EE, Elliott DM, Mauck RL (2009) Nanofibrous biologic laminates replicate the form and function of the annulus fibrosus. Nat Mater 8: 986-992.

Nieponice A, Maul TM, Cumer JM, Soletti L, Vorp DA (2007) Mechanical stimulation induces morphological and phenotypic changes in bone marrow-derived progenitor cells within a three-dimensional fibrin matrix. J Biomed Mater Res A 81: 523-530.

O'Connell GD, Vresilovic EJ, Elliott DM (2010) Human intervertebral disc internal strain in compression: The effect of disc region, loading position, and degeneration. J Orthop Res., in press.

Passaretti D, Silverman RP, Huang W, Kirchhoff CH, Ashiku S, Randolph MA, Yaremchuk MJ (2001) Cultured chondrocytes produce injectable tissue-engineered cartilage in hydrogel polymer. Tissue Eng 7: 805-815.

Peretti GM, Xu JW, Bonassar LJ, Kirchhoff CH, Yaremchuk MJ, Randolph MA(2006) Review of injectable cartilage engineering using fibrin gel in mice and swine models. Tissue Eng 12: 1151-1168.

Rowe SL, Lee S, Stegemann JP (2007) Influence of thrombin concentration on the mechanical and morphological properties of cell-seeded fibrin hydrogels. Acta Biomater 3: 59-67.

Sato M, Asazuma T, Ishihara M, Kikuchi T, Masuoka K, Ichimura S, Kikuchi M, Kurita A, Fujikawa K (2003) An atelocollagen honeycomb-shaped scaffold with a membrane seal (ACHMS-scaffold) for the culture of annulus fibrosus cells from an intervertebral disc. J Biomed Mater Res A 64: 248-256. 
Schlegel JD, Smith JA, Schleusener RL (1996) Lumbar motion segment pathology adjacent to thoracolumbar, lumbar, and lumbosacral fusions. Spine (Phila Pa 1976) 21: 970-981.

Sebastine IM, Williams DJ (2007) Current developments in tissue engineering of nucleus pulposus for the treatment of intervertebral disc degeneration. Conf Proc IEEE Eng Med Biol Soc 2007: 6401-6406.

Sell SA, Francis MP, Garg K, McClure MJ, Simpson DG, Bowlin GL (2008) Cross-linking methods of electrospun fibrinogen scaffolds for tissue engineering applications. Biomed Mater 3: 45001.

Shao X, Hunter CJ (2007) Developing an alginate/ chitosan hybrid fiber scaffold for annulus fibrosus cells. J Biomed Mater Res A 82: 701-710.

Starcher B (2001) A ninhydrin-based assay to quantitate the total protein content of tissue samples. Anal Biochem 292: 125-129.

Sun J, Zheng Q, Wu Y, Liu Y, Guo X, Wu W (2010) Biocompatibility of KLD-12 peptide hydrogel as a scaffold in tissue engineering of intervertebral discs in rabbits. $\mathrm{J}$ Huazhong Univ Sci Technolog Med Sci 30: 173-177.

Sung HW, Huang RN, Huang LL, Tsai CC (1999) In vitro evaluation of cytotoxicity of a naturally occurring cross-linking reagent for biological tissue fixation. J Biomater Sci Polym Ed 10: 63-78.

Sung HW, Chang WH, Ma CY, Lee MH (2003) Crosslinking of biological tissues using genipin and/or carbodiimide. J Biomed Mater Res A 64: 427-438.

Touyama R, Inoue K, Takeda Y, Yatsuzuka M, Ikumoto T, Moritome N, Shingu T, Yokoi T, Intuye H (1994) Studies on the blue pigments produced fromgenipin and methylamine II: The formation mechanisms of brownishred intermediates leading to the blue pigment formation. Chem Pham Bull 42: 1571-1578.
Tsai CC, Huang RN, Sung HW, Liang HC (2000) In vitro evaluation of the genotoxicity of a naturally occurring crosslinking agent (genipin) for biologic tissue fixation. J Biomed Mater Res 52: 58-65.

Wan Y, Feng G, Shen FH, Balian G, Laurencin CT, Li X (2007) Novel biodegradable poly(1,8-Octanediol Malate) for annulus fibrosus regeneration. Macromol Biosci 7: 1217-1224.

Wan Y, Feng G, Shen FH, Laurencin CT, Li X (2008) Biphasic scaffold for annulus fibrosus tissue regeneration. Biomaterials 29: 643-652.

Wilke HJ, Heuer F, Neidlinger-Wilke C, Claes L (2006) Is a collagen scaffold for a tissue engineered nucleus replacement capable of restoring disc height and stability in an animal model? Eur Spine J 15 Suppl 3: S433-438.

Yamazaki M, Chiba K, Yoshikawa C (2009) Genipin suppresses A23187-induced cytotoxicity in Neuro2a cells. Biol Pharm Bull 32: 1043-1046.

Yang L, Kandel RA, Chang G, Santerre JP (2009) Polar surface chemistry of nanofibrous polyurethane scaffold affects annulus fibrosus cell attachment and early matrix accumulation. J Biomed Mater Res A 91: 1089-1099.

Yao CH, Liu BS, Chang CJ, Hsu SH, Chen YS (2004) Preparation of networks of gelatin and genipin as degradable biomaterials. Mater Chem and Phys 83: 204208.

Zhang YH, Zhao CQ, Jiang LS, Dai LY (2011) Substrate stiffness regulates apoptosis and the mRNA expression of extracellular matrix regulatory genes in the rat annular cells. Matrix Biol 30: 135-144.

Editor's Note: All questions/comments by the reviewers were answered by text changes; hence, there is no "Discussion with Reviewers" section. 